\title{
Environmentalist kangaroos for human consumption?
}

Sydney

Moves are afoot to change the status of Australia's national symbol, the kangaroo, from vermin to valued commercial resource. According to Professor Gordon Grigg, of the University of Sydney's department of biology, a switch from sheep to kangaroo farming is the only way to halt the desertification of vast tracts of Australia's rangelands in western New South Wales.

Grigg advocates a system where a wildlife inspector would assess the number of kangaroos on a property and issue tags according to the permissible harvest. The kangaroos would be shot on the property, and immediately loaded into refrigerated trucks. Only carcasses with tags attached would be allowed to be processed. Kangaroo meat is compared to venison and is very nutritious, containing only 1 per cent fat compared with the 40 per cent fat ratio of cattle or sheep.

Grigg says the arid rangeland has been severely damaged by the hard hooves of sheep and cattle. "The land is crisscrossed with tracks and beaten to powder", he says, because of overgrazing. As the land becomes more barren, farmers are turning in economic desperation to goats which will eat the woody shrubs left by the sheep. Griggs believes the widespread introduction of goats would be the final ecological blow.

With free-range kangaroos, animals will be able to move to greener pastures in a drought year, with only a sustainable number staying behind. Destruction of

\section{No more high-energy}

Washington

APPARENTLy trying to stir up debate, the National Science Foundation (NSF) went to some trouble last week to encourage speculation that the $\$ 42$ million it spends each year on high-energy physics might be discontinued. But when questioned, NSF officials played down the idea, and would say only that spending in many areas was being discussed and that high-energy physics was not especially threatened.

In a speech to a joint meeting of the American Physical Society and the American Association of Physics Teachers, Erich Bloch, director of NSF, wondered whether the money that NSF spends on high-energy physics might not more usefully be spent in other ways, leaving high-energy physics entirely in the hands of the Department of Energy (DoE). NSF received only a 3 per cent increase in last year's federal budget, and may now be looking to shed some of its the land would be reversed, according to Grigg, as the kangaroo is a soft-footed grazer eating only the tops of grasses and leaving enough of the plant for it to recover. Seeds eaten by the kangaroo pass undamaged through its system.

Large-scale kangaroo farming has not taken off yet because every state of Australia except South Australia prohibits the

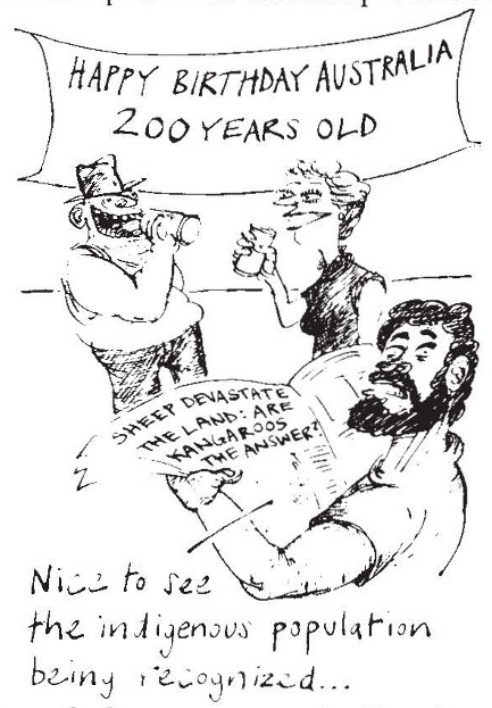

sale of kangaroo meat for human consumption.

Australia's influential conservation movement is split over the issue. Some factions are opposed to the economic exploitation of any animal, but others believe that the preservation of habitat takes precedence over manipulation of a single species.

Charles Morgan

\section{physics for NSF?}

long-standing programmes to press ahead with new ones, particularly its science and technology centres.

Although NSF's spending in highenergy physics is only 8 per cent of the US total, it supports about one-third of university research. Roy Schwitters of Harvard University, a former adviser to NSF, says that NSF money goes principally to small groups and departments, and supports a wide range of research efficiently and inexpensively. NSF's flexibility gives it a disproportionate influence compared with DoE, much of whose spending is on big programmes.

Bloch has spoken favourably in the past of NSF's role in high-energy physics, and may be airing his thoughts in public to draw physicists to his defence. The less appealing alternative is that unloading high-energy physics is a serious intention, and he wants to gauge the opposition before making moves.

\section{Sakharov work acknowledged}

\section{London}

THE official Soviet news agency TASS has unexpectedly put out on its foreign service an account of the cosmological theories of Dr Andrei Sakharov. Since his return to Moscow from Gor'kii in December 1986, Sakharov has received occasional notices from the Soviet media, but these have been almost entirely connected with his opposition to nuclear weapons and his support for glasnost. Virtually nothing has been said of him as a scientist, and the drive to "rejuvenate" the Academy of Sciences made it unlikely that Sakharov, at 66 , would return to full-time research.

Nevertheless, in 1980, when Sakharov was exiled to Gor'kii, some Soviet officials said that by removing Sakharov from the proximity of Western journalists and his fellow-dissidents, they were taking him out of the way of temptation, and providing an academic seclusion in which he could return to research. Sakharov's own accounts of his conditions of exile do not bear out this picture but he did produce during these years some papers on cosmological theory which appeared in due course in the Zhurnal Eksperimental'noi $i$ Teoreticheskoi Fiziki.

The TASS account deals primarily with Sakharov's latest hypothesis of the existence of a parallel universe of shadow particles that interact only gravitationally whose existence might be demonstrable through observations of black holes. These shadow particles, TASS quotes Sakharov as saying, would be emitted simultaneously with "the particles known to science", during the evaporation of black holes. The rate of evaporation would then be twice that expected if only "known" particles were involved. If a black hole can be discovered, and its rate of evaporation observed, the existence of shadow particles could be established

This hypothesis, however, is presented as a continuation of the "cycle" of Sakharov's work "of the past decade". (The commentator refers in particular to his 1984 paper postulating that time is multidimensional.) The term "cycle" in this context is significant. For the past few years, State and Lenin prizes for science have been awarded not for individual discoveries but for "cycles" of work over a prolonged period. The implication here is that Sakharov has been working consistently and productively at his cosmology, without interruption. In spite of glasnost, official Soviet biographies of "rehabilitated" people still pass in silence over their years in prison or labour camp. And, glasnost notwithstanding, Sakharov's years of internal exile seem likely to vanish in the same way.

Vera Rich 